\title{
Small-Scale Forward Smouldering Experiments for Remediation of Coal Tar in Inert Media
}

\author{
Paolo Pironi, Christine Switzer, Guillermo Rein, Jason I. Gerhard1, Jose L. Torero \\ BRE Centre for Fire Safety Engineering \\ University of Edinburgh, UK \\ Andres Fuentes \\ Ecole Polytechnique Universitaire de Marseille, France
}

\begin{abstract}
This paper presents a series of experiments conducted to assess the potential of smouldering combustion as a novel technology for remediation of contaminated land by water-immiscible organic compounds. The results from a detailed study of the conditions under which a smouldering reaction propagates in sand embedded with coal tar are presented. The objective of the study is to provide further understanding of the governing mechanisms of smouldering combustion of liquids in porous media. A small-scale apparatus consisting of a $100 \mathrm{~mm}$ in diameter quartz cylinder arranged in an upward configuration was used for the experiments. Thermocouple measurements and visible digital imaging served to track and characterize the ignition and propagation of the smouldering reaction. These two diagnostics are combined here to provide valuable information on the development of the reaction front. Post-treatment analyses of the sand were used to assess the amount of coal tar remaining in the soil. Experiments explored a range of inlet airflows and fuel concentrations. The smouldering ignition of coal tar was achieved for all the conditions presented here and self-sustained propagation was established after the igniter was turned off. It was found that the combustion is oxygen limited and peak temperatures in the range $800-1080{ }^{\circ} \mathrm{C}$ were observed. The peak temperature increased with the airflow at the lower range of flows but decreased with airflow at the higher range of flows. Higher airflows were found to produce faster propagation. Higher fuel concentrations were
\end{abstract}

\footnotetext{
${ }^{1}$ Now at: Department of Civil and Environmental Engineering, University of Western Ontario, Canada,
} 
Ref: P Pironi, C Switzer, G Rein, JI Gerhard, JL Torero, A Fuentes, Small-Scale Forward Smouldering Experiments for Remediation of Coal Tar in Inert Media, Proceedings of the Combustion Institute 32 (2), pp. 1957-1964, 2009. http://dx.doi.org/10.1016/j.proci.2008.06.184. Free access version at http://www.era.lib.ed.ac.uk/handle/1842/1152

found to produce higher peak temperatures and slower propagation. The measured mass removal of coal tar was above $99 \%$ for sand obtained from the core and $98 \%$ for sand in the periphery of the apparatus.

Keywords: NAPL; technology; clean-up; soil; smoldering

\section{Introduction}

Nonaqueous phase liquids (NAPLs) are a class of organic compounds with a long history of extensive use in industrial processes. As the result of inappropriate disposal practices, NAPLs are now among the most frequently occurring contaminants detected in the subsurface throughout the industrialized world [1]. Most of these contaminants are toxic to humans and the environment in high, acute doses and may be irritants and suspected carcinogens at low, chronic doses. Standard handling and disposal procedures resulted in widespread releases of these chemicals into the environment, creating persistent, long-term sources of groundwater contamination. Existing in soil pores as a separate liquid phase, NAPL dissolve in groundwater in amounts high enough to render it unfit for consumption, but low enough such that its lifespan can be on the order of centuries [2]. Remediation of NAPL-contaminated soil in a cost effective and robust manner remains a significant challenge.

A proposed NAPL remediation approach is destruction by combustion. Many common NAPLs, such as trichloroethylene, petrochemicals or coal tar have heats of combustion in excess of other wastes that are successfully burnt in other industries (e.g. biomass energy, waste incineration). Such industries typically employ flaming combustion to release the heat from the waste and often require additional fuel to sustain the burning process. However, a 
Ref: P Pironi, C Switzer, G Rein, JI Gerhard, JL Torero, A Fuentes, Small-Scale Forward Smouldering Experiments for Remediation of Coal Tar in Inert Media, Proceedings of the Combustion Institute 32 (2), pp. 1957-1964, 2009. http://dx.doi.org/10.1016/j.proci.2008.06.184. Free access version at http://www.era.lib.ed.ac.uk/handle/1842/1152

flame cannot be sustained within the porous media that comprises the subsurface and thus is not a viable technique for soil remediation. Prior to the results of these experiments, the authors hypothesized that smouldering combustion of the organic liquid within the porous matrix can be sustained and propagate, resulting in NAPL destruction and some level of soil remediation.

Little work on smouldering combustion exists and this application has, to the knowledge of the authors, never been explored. Prior to the potential implementation of this new approach, a detailed understanding of the mechanisms controlling ignition and propagation of smouldering of organic liquids embedded in a porous medium is required. This paper presents an initial suite of bench-top experiments that describe the conditions under which a smouldering reaction will propagate in soil embedded with a NAPL. These experiments serve to characterize the reaction and to establish the conditions leading to ignition and propagation that will enable its assessment as a viable remediation technique. A sample fuel, coal tar, has been selected for this paper because it is relatively amenable to ignition and the smouldering reaction is strong (i.e., can be directed away from extinction conditions). This fuel is one of many NAPLs that have been successfully ignited as part of the investigation of the burning conditions for other fuels, whose results are reported elsewhere [3].

Coal tar is a dark-colour NAPL that is typically 1.1 times denser and 160 times more viscous than water at ambient temperatures. It is a by-product of the carbonization of coal to produce coke and/or natural gas and does not occur naturally. Coal tar contains a large number of polycyclic aromatic hydrocarbons (PAHs), phenols, heterocyclic oxygen, sulphur, and nitrogen compounds and is considered carcinogenic to humans. Subsurface contamination with coal tar exists today as a result of uncontrolled disposal of process residuals at former manufactured gas plants, which were situated in most towns and cities in the industrialized world during the late $19^{\text {th }}$ and early $20^{\text {th }}$ centuries. There are more than 
Ref: P Pironi, C Switzer, G Rein, JI Gerhard, JL Torero, A Fuentes, Small-Scale Forward Smouldering Experiments for Remediation of Coal Tar in Inert Media, Proceedings of the Combustion Institute 32 (2), pp. 1957-1964, 2009. http://dx.doi.org/10.1016/j.proci.2008.06.184. Free access version at http://www.era.lib.ed.ac.uk/handle/1842/1152

1,000 coal-tar contaminated sites catalogued in the United States alone [4]. Conventional remediation methods, such as direct extraction via pumping or groundwater pump-andtreat, have been demonstrated as unable to effectively restore these sites [1].

This paper presents a series of small-scale experiments conducted on sand containing coal tar to assess the potential of smouldering combustion as a novel technology for remediation of contaminated land by water-immiscible organic compounds.

\section{Smouldering in Porous Media}

Flaming combustion in inert porous media has been studied extensively as a mechanism to control heat losses from combustion reactions and thus allow the burning of low calorific output fuels or very lean mixtures [5]. The enabling factor is the effective retention of heat by the inert porous matrix but its most significant limitation is the need for the fuel to be in the gas phase; thus flaming this is not a viable technique for soil remediation and it will not be further discussed here.

An alternative process occurring in porous media and benefiting from the same advantageous heat transfer is smouldering combustion. Smouldering combustion is the flameless burning of a condensed fuel that derives heat from surface oxidation reactions [6]. It generally burns through a wide range of temperatures, is oxygen deficient, spreads slowly and can infiltrate deep into a porous domain. It involves processes related to fluid flow, heat transfer and heterogeneous chemical reactions. In general, a smouldering fuel consists of an aggregate and permeable medium formed by particulates, grains, fibres or a porous matrix. These aggregate fuel elements provide (i) a large surface area per unit volume that enhance surface reactions, (ii) thermal insulation that reduces heat losses, and (iii) permeability to oxygen transport to the reaction sites by convection and diffusion. 
Ref: P Pironi, C Switzer, G Rein, JI Gerhard, JL Torero, A Fuentes, Small-Scale Forward Smouldering Experiments for Remediation of Coal Tar in Inert Media, Proceedings of the Combustion Institute 32 (2), pp. 1957-1964, 2009. http://dx.doi.org/10.1016/j.proci.2008.06.184. Free access version at http://www.era.lib.ed.ac.uk/handle/1842/1152

Smouldering combustion of solid fuels has been the focus of fundamental research and its characteristics have been studied mostly in fire safety and material synthesis. Material synthesis studies have been reviewed by Merzanov \& Khaikin [7] and fire safety researches refer mostly to polyurethane foam [8,9] and cellulose [6]. Studies on incineration processes involving smouldering are unusual; the best known are Salganskii [10] and Vantelon et al. [11].

The smouldering of liquid fuels embedded in an inert porous matrix is also possible. There are two examples of this in the literature. Well known in fire safety engineering are lagging fires, which are fires initiated inside insulating materials (the porous medium) soaked in oils and other self-igniting liquids [12]. In addition, in the petroleum industry, smouldering fronts are purposely initiated in deep underground reservoirs to drive a fraction of the oil towards the extraction port to enhance recovery (e.g., [13]). There is very little work published on the mechanisms governing the smouldering of liquids.

Once ignition occurs, the smoulder reaction advances gradually through the material. The net heat released by the reactions is partially transferred by conduction, convection and radiation ahead of the reaction and partially lost to the environment. The oxidizer is transported to the reaction zone by diffusion and convection, in turn feeding the oxidation reactions. It is well established that for most materials and typical conditions, the two limiting factors in smouldering propagation are the oxidizer flux to, and the heat losses from, the reaction zone $[6,8,9]$. Smouldering combustion can propagate in two distinctive modes, forward and opposed, depending on the relative direction of the oxidizer flow. Forward propagation, the mode employed in this study, is the most energy efficient mode of propagation since in this configuration the oxidizer flows through the reaction and the energy is used to preheat the fuel and porous matrix ahead of the reaction front $[6,7]$. 
Ref: P Pironi, C Switzer, G Rein, JI Gerhard, JL Torero, A Fuentes, Small-Scale Forward Smouldering Experiments for Remediation of Coal Tar in Inert Media, Proceedings of the Combustion Institute 32 (2), pp. 1957-1964, 2009. http://dx.doi.org/10.1016/j.proci.2008.06.184. Free access version at http://www.era.lib.ed.ac.uk/handle/1842/1152

\section{Experimental Setup}

For this set of experiments, a sample holder $100 \mathrm{~mm}$ in diameter was identified as large enough to sustain smouldering but small enough to allow for a time-efficient exploration of the phenomena. The reaction front is started by an igniter and the propagation is aided by a forced flow of air.

Figure 1 presents a schematic diagram of the experimental apparatus. Upward smouldering combustion tests were carried out in a 1L quartz glass cylindrical beaker $100 \mathrm{~mm}$ in diameter and $175 \mathrm{~mm}$ in height. Commercial grade fresh coal tar was employed (Alfa Aesar, Heysham, UK) exhibiting a density of $1.2 \mathrm{~kg} / \mathrm{L}$ at room temperature. The inert sand (Leighton Buzzard 8/16 sand, WBB Minerals, UK) is characterized by a bulk density of $1.7 \mathrm{~kg} / \mathrm{L}$, porosity of 0.40 after packing, and grain diameters of $1-2 \mathrm{~mm}$. The fuel/sand mixture was prepared by mixing coal tar and sand in a mass ratio corresponding to the desired NAPL saturation (where NAPL saturation is defined as the volume fraction of pore space occupied by NAPL). The base case NAPL saturation was $25 \%$, corresponding to $0.12 \mathrm{~kg}$ coal tar per L sand.

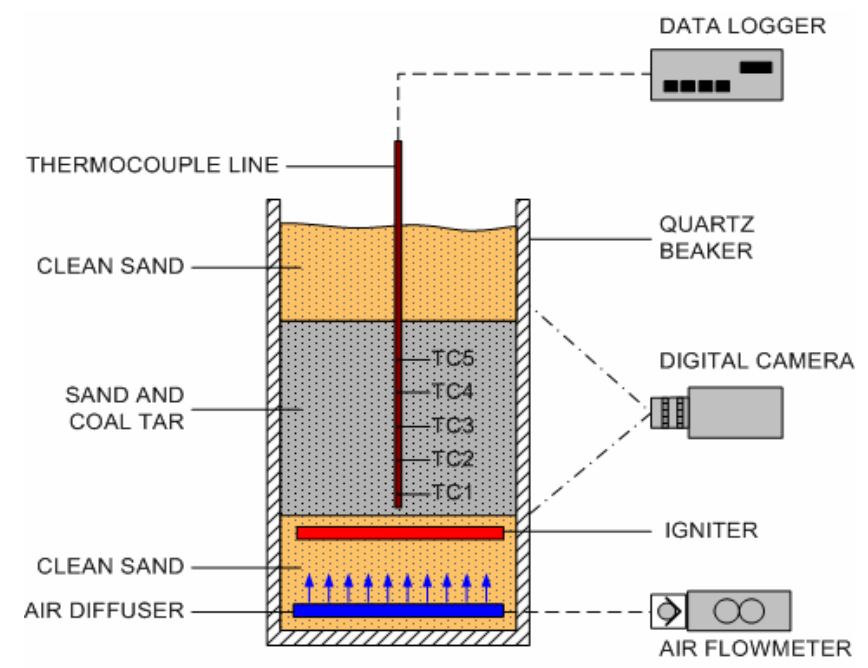

Figure 1. Schematic of the experimental apparatus in cross-section. 
Ref: P Pironi, C Switzer, G Rein, JI Gerhard, JL Torero, A Fuentes, Small-Scale Forward Smouldering Experiments for Remediation of Coal Tar in Inert Media, Proceedings of the Combustion Institute 32 (2), pp. 1957-1964, 2009. http://dx.doi.org/10.1016/i.proci.2008.06.184. Free access version at http://www.era.lib.ed.ac.uk/handle/1842/1152

Each sample was prepared in layers (see Figure 1). A layer of clean sand was placed at the bottom of the beaker up to a height of $40 \mathrm{~mm}$. Then the air diffuser was installed, which consisted of a $70 \mathrm{~mm}$ diameter bronze porous disc, brazed to a structural support. Additional sand was used to bury the air diffuser by a few millimetres. Emplaced next was the igniter, a $3.25 \mathrm{~mm}$ square cross section $\times 762 \mathrm{~mm}$ length inconel cable heater $(240 \mathrm{~V}, 450 \mathrm{~W}$, Watlow Ltd, UK) formed into a flat spiral of $80 \mathrm{~mm}$ maximum external diameter. Then a $60 \mathrm{~mm}$ layer of the coal tar/sand mixture at the desired saturation was added. A final $30 \mathrm{~mm}$ layer of clean sand was emplaced at the top of the sample and in contact with the free surface. The igniter was placed at the bottom and upward propagation was chosen because buoyancy favours forward propagation. For this initial study it was chosen to explore the dependence of the process on the two dominant variables, oxidant injection rate and fuel content. Experiments were therefore conducted at different air fluxes fixing the fuel saturation, and at different NAPL saturation levels fixing the air flux. The values of the inlet air flux were calculated by referring the measured volumetric flow rate to atmospheric pressure and dividing it by the horizontal cross-sectional area of the beaker.

Five $1.5 \mathrm{~mm} \times 0.5 \mathrm{~m}$ inconel sheath Type $\mathrm{K}$ thermocouples were driven into the sand pack, with their junctions located on the beaker axis, at approximately $10 \mathrm{~mm}$ intervals above the cable heater. The thermocouples were connected to a data acquisition system (Multifunction Switch/Measure Unit 34980A, Agilent Technologies). Digital visual images of the process were taken every $10 \mathrm{~s}$ using a CCD monochrome camera (Axis 206M Megapixel Network Camera) at a 640x480 dpi resolution.

The experimental system was preheated to a starting temperature of approximately $400{ }^{\circ} \mathrm{C}$, measured at the location of the lowest thermocouple (TC1). This starting temperature was 
Ref: P Pironi, C Switzer, G Rein, JI Gerhard, JL Torero, A Fuentes, Small-Scale Forward Smouldering Experiments for Remediation of Coal Tar in Inert Media, Proceedings of the Combustion Institute 32 (2), pp. 1957-1964, 2009. http://dx.doi.org/10.1016/j.proci.2008.06.184. Free access version at http://www.era.lib.ed.ac.uk/handle/1842/1152

determined from previous testing as the minimum temperature that ensures sample ignition in the selected inlet airflow range. Preheating required $1 \mathrm{~h}$ on average and was carried out by supplying the igniter with progressively increasing power so as to maintain approximately constant the rate of temperature rise at TC1. The maximum power used for these experiments was approximately $320 \mathrm{~W}$, which corresponds to a heat flux of $41 \mathrm{~kW} / \mathrm{m}^{2}$ over the cross-sectional area of the beaker. A low air flux of $0.6 \mathrm{~cm} / \mathrm{s}$ was maintained during the preheating period to prevent clogging of the air diffuser or the sand pack. Once the starting temperature was achieved, the air flux was increased instantly to the predetermined level and maintained until the end of the experiment. The igniter was turned off when the temperature measured by the thermocouple TC2 began to decrease with time (i.e., postpeak). This preheating and ignition protocol is analogous to that used in [8,9] to study the smouldering of polyurethane foam, but adapted to the new fuel characteristics.

The rate of smoulder propagation was obtained using two independent experimental measurements: temperature histories and digital images. Based on temperature histories, the smouldering velocity was calculated from the time lapse of the front arrival at two consecutive thermocouples and the known separation distance. The time of arrival of the reaction front at a certain thermocouple location in the centre of the sand pack is estimated as the average of the times at which the temperature reaches three predetermined values (either $500 / 600 / 700{ }^{\circ} \mathrm{C}$ or $600 / 700 / 800{ }^{\circ} \mathrm{C}$ depending on the peak temperature), all of which are above the observed ignition temperature.

In addition, images from the digital camera captured the movement of the glowing part of the smouldering front at the edges of the sample (Fig. 5). The propagation of this visible front was described by processing the images to track the movement of its leading and trailing edges. Image capture and analysis is a diagnostic technique commonly used in the study of smouldering reactions in material synthesis and filtering combustion [7]. The combined use 
Ref: P Pironi, C Switzer, G Rein, JI Gerhard, JL Torero, A Fuentes, Small-Scale Forward Smouldering Experiments for Remediation of Coal Tar in Inert Media, Proceedings of the Combustion Institute 32 (2), pp. 1957-1964, 2009. http://dx.doi.org/10.1016/j.proci.2008.06.184. Free access version at http://www.era.lib.ed.ac.uk/handle/1842/1152

of digital imaging and invasive thermocouple probing is a distinctive characteristic of these experiments, made possible by the strongly reacting coal tar and the unconsolidated, particulate inert media. In other contexts of smoulder research the materials under study are either reacting too weakly to be visually detected (e.g., in fire safety engineering $[6,8,9])$ or not susceptible to invasive data acquisition techniques (e.g., in material synthesis [7]).

During the experiment, the presence of $\mathrm{CO}$ and $\mathrm{CO}_{2}$ gases at the free surface in significant amounts was measured as an indicator that a combustion reaction was occurring inside the sand pack. Post-treatment analysis of the samples was conducted to assess contaminant destruction as an indication of the remediation efficacy of the process.

\section{Experimental Observations and Results}

\subsection{Thermocouple Results Varying Air Flux at Fixed NAPL Saturation}

The first set of experiments was conducted at forced air fluxes of 2.29, 4.75, 7.94, and $16.2 \mathrm{~cm} / \mathrm{s}$ for an initial coal tar saturation of $25 \%$. Characteristic temperature time histories for two of these are presented in Figure 2. Figure 2(b) also indicates the incremental power supplied to the heater during the experiment. The preheating period lasted approximately 50 min and during this period changes in the power supplied resulted in changes of the slope of the temperature-time histories, which are particularly pronounced for the locations closer to the igniter (thermocouples TC1 and TC2). Thermocouple histories of the form presented in Figure 2 are the main diagnostic technique to study smouldering combustion in fire safety engineering $[8,9]$. 
Ref: P Pironi, C Switzer, G Rein, JI Gerhard, JL Torero, A Fuentes, Small-Scale Forward Smouldering Experiments for Remediation of Coal Tar in Inert Media, Proceedings of the Combustion Institute 32 (2), pp. 1957-1964, 2009. http://dx.doi.org/10.1016/j.proci.2008.06.184. Free access version at http://www.era.lib.ed.ac.uk/handle/1842/1152
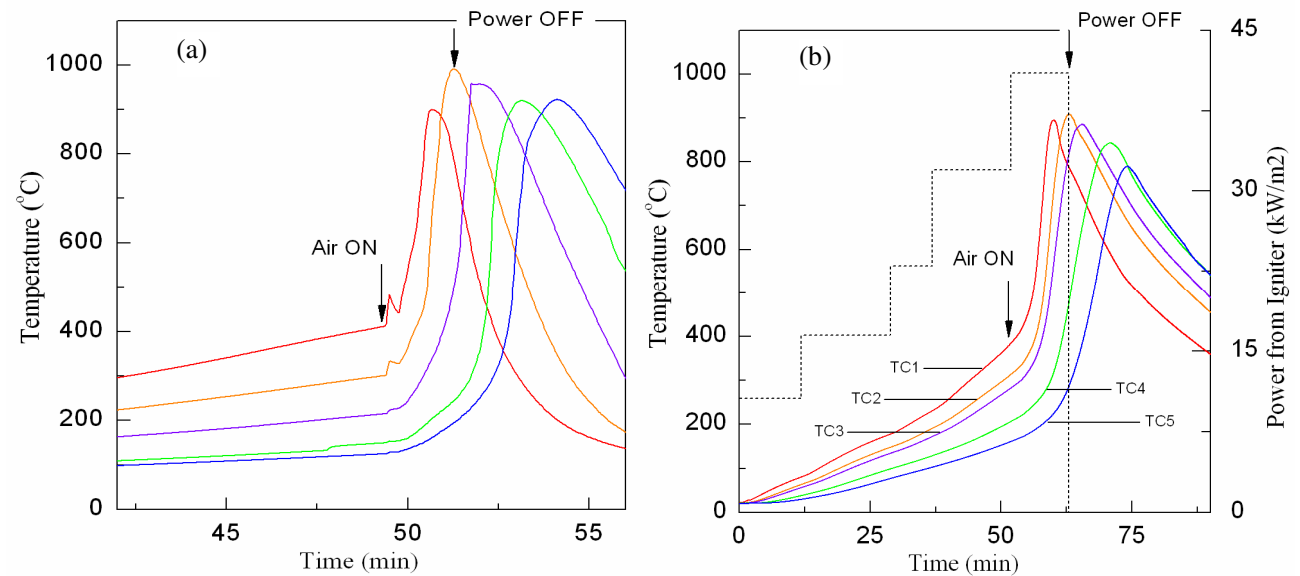

Figure 2.Temperature histories along the sample centre axis for a coal tar saturation of $25 \%$ and air flux of (a) $16.2 \mathrm{~cm} / \mathrm{s}$ and (b) $2.29 \mathrm{~cm} / \mathrm{s}$. In (b) the dotted line indicates power supplied to the heater (right hand vertical axis).

Ignition of the fuel is indicated by TC1 (closest to the igniter, see Figure 1), and signalled by the measured rapid temperature increase. This ignition occurred either immediately or only a few minutes after the onset of air injection, but always at temperatures greater than $400{ }^{\circ} \mathrm{C}$, This indicates that the ignition temperature for smouldering coal tar is lower and in the vicinity of $400{ }^{\circ} \mathrm{C}$. The nature of the preheating period was explored in detail (data not shown), during which it was observed that an optimal heating rate was essential to attain ignition.

After a location experiences the rapid heating indicative of the onset of smouldering, the temperature reaches a maximum and then starts decreasing as the reaction passes. A succession of similar temperature peaks at successive locations after the igniter is terminated indicates the self-sustained upward propagation of the reaction away from the ignition zone. In some cases, such as the one presented in Figure $2 b$, the reaction weakens significantly before reaching the top end of the sample as suggested by the temperature history of TC5, which fails to exceed the temperature of the previous thermocouple. 
Ref: P Pironi, C Switzer, G Rein, JI Gerhard, JL Torero, A Fuentes, Small-Scale Forward Smouldering Experiments for Remediation of Coal Tar in Inert Media, Proceedings of the Combustion Institute 32 (2), pp. 1957-1964, 2009. http://dx.doi.org/10.1016/j.proci.2008.06.184. Free access version at http://www.era.lib.ed.ac.uk/handle/1842/1152

The relationship between the average smouldering velocity and the air flux is presented in Figure 3. The results indicate a nearly linear dependence of the propagation velocity with air flux for values above $2.29 \mathrm{~cm} / \mathrm{s}$. This trend has been observed before and is typical of oxygen-limited smouldering propagation [8,9]. The variation of the peak smouldering temperature along the sample is presented in Figure 4 for the different air fluxes. Peak temperatures at each location ranging from $789^{\circ} \mathrm{C}$ to $1073{ }^{\circ} \mathrm{C}$ were observed, with the highest values attained for the $4.75 \mathrm{~cm} / \mathrm{s}$ air flux experiment. The peak temperatures for $7.94 \mathrm{~cm} / \mathrm{s}$ and $16.2 \mathrm{~cm} / \mathrm{s}$ are very similar and any differences observed in Figure 4 are within the measurement uncertainty of these experiments. These results reveal that, within the studied range of air fluxes, higher velocities result in faster propagation but not necessarily in higher temperatures. This is typical of combustion in porous media and is mainly associated to the fine balance between oxygen consumption and heat transfer.

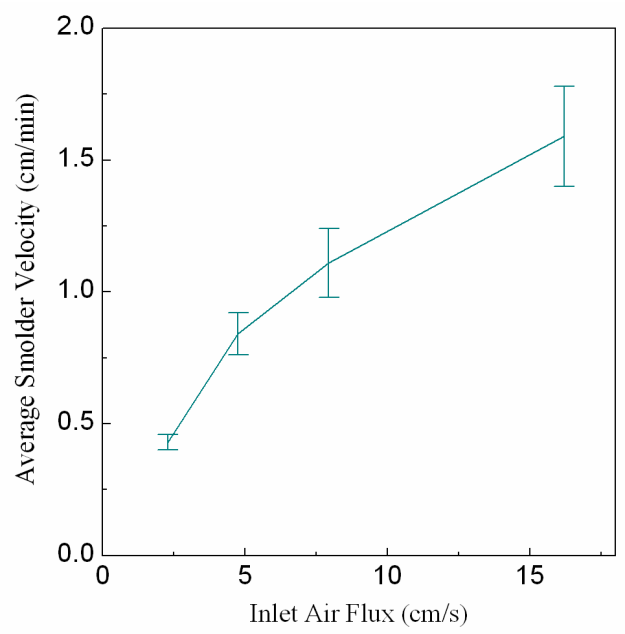

Figure 3. Average smouldering velocity as a function of the air flux.

As indicated by Figure 4, peak temperatures are higher in the middle of the sample and decay towards the top. The observed decay of the peak temperatures in these experiments 
Ref: P Pironi, C Switzer, G Rein, JI Gerhard, JL Torero, A Fuentes, Small-Scale Forward Smouldering Experiments for Remediation of Coal Tar in Inert Media, Proceedings of the Combustion Institute 32 (2), pp. 1957-1964, 2009. http://dx.doi.org/10.1016/j.proci.2008.06.184. Free access version at http://www.era.lib.ed.ac.uk/handle/1842/1152

may be attributed to the influence of the heat from the igniter. At locations distant from the igniter heat losses have a relatively large effect and hamper smouldering propagation, reducing the peak temperature. It is therefore expected that for some of the weaker smouldering fronts obtained here, results in a taller column may show extinction of the reaction at some further distance from the igniter. Figure 4 suggests that only for the 2.29 $\mathrm{cm} / \mathrm{s}$ air flux the reaction approaches extinction conditions as it reaches the end of the sample. This is consistent with the break-up of the linear dependence of the propagation velocity with air flux at lower values presented in Figure 3. It is important to note that, in such systems, the relative significance of heat losses decreases as the diameter of the sample increases; thus a stronger smouldering process is expected as the sample is scaled-up. A more detailed analysis of the effect of heat losses and sample size in smouldering processes is presented in [9].

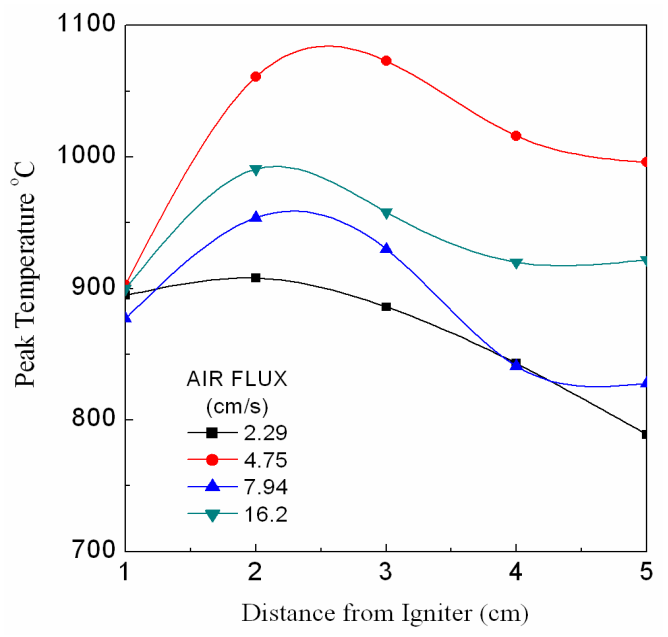

Figure 4. Variation of the smouldering reaction maximum temperature along the sample for several air fluxes.

\subsection{The Influence of Fuel Saturation}

The second set of experiments varied the fuel saturation of the sand. The amount of coal tar mixed into the soil for each case was $0.048 \mathrm{~kg} / \mathrm{L}(10 \%$ NAPL saturation), $0.12 \mathrm{~kg} / \mathrm{L}(25 \%)$ 
Ref: P Pironi, C Switzer, G Rein, JI Gerhard, JL Torero, A Fuentes, Small-Scale Forward Smouldering Experiments for Remediation of Coal Tar in Inert Media, Proceedings of the Combustion Institute 32 (2), pp. 1957-1964, 2009. http://dx.doi.org/10.1016/j.proci.2008.06.184. Free access version at http://www.era.lib.ed.ac.uk/handle/1842/1152

and $0.24 \mathrm{~kg} / \mathrm{L}(50 \%)$. The inlet air flux was maintained at $4.75 \mathrm{~cm} / \mathrm{s}$. The propagation velocities and peak temperatures for these experiments are presented in Table 1.These results indicate that as the saturation increases the smoulder velocity decreases in a roughly linear fashion, which confirms that for this saturation range and air flux the reaction is oxygen limited. The results also indicate that the peak temperature increases with saturation. However, the temperature increment is much more pronounced when saturation is increased from $10 \%$ to $25 \%$ than from $25 \%$ to $50 \%$; in other words, the temperature does not depend linearly on saturation above $25 \%$ but seems to approach an asymptotic value.

Table 1. Dependence of Forward Smouldering on Fuel Saturation.

\begin{tabular}{cccc}
\hline Saturation & $\mathbf{1 0 \%}$ & $\mathbf{2 5 \%}$ & $\mathbf{5 0 \%}$ \\
\cline { 2 - 4 } $\begin{array}{c}\text { Average smoulder velocity } \\
(\mathrm{cm} / \mathrm{min})\end{array}$ & 0.94 & 0.84 & 0.61 \\
Average peak temperature $\left({ }^{\circ} \mathrm{C}\right)$ & 784 & 1010 & 1045 \\
\hline
\end{tabular}

4.3 Comparison with Results from Digital Imaging

Figure 5 presents a sequence of images corresponding to an experiment at an air flux of $16.2 \mathrm{~cm} / \mathrm{s}$ and a coal tar saturation of $25 \%$. Similar observations could be made for other conditions. The images were chosen for temporal coincidence with the leading edge of the visible front reaching TC1 (Figure 5a), TC2 (Figure 5b), TC4 (Figure 5c) and TC5 (Figure 5d). Images from the outside of the beaker can only capture the visible phenomena taking place within a layer near the edge of the sample. Thus they do not provide a direct indication of the smouldering reaction in the core of the sample. However, they provide a qualitative description of the propagation process. 
Ref: P Pironi, C Switzer, G Rein, JI Gerhard, JL Torero, A Fuentes, Small-Scale Forward Smouldering Experiments for Remediation of Coal Tar in Inert Media, Proceedings of the Combustion Institute 32 (2), pp. 1957-1964, 2009. http://dx.doi.org/10.1016/j.proci.2008.06.184. Free access version at http://www.era.lib.ed.ac.uk/handle/1842/1152

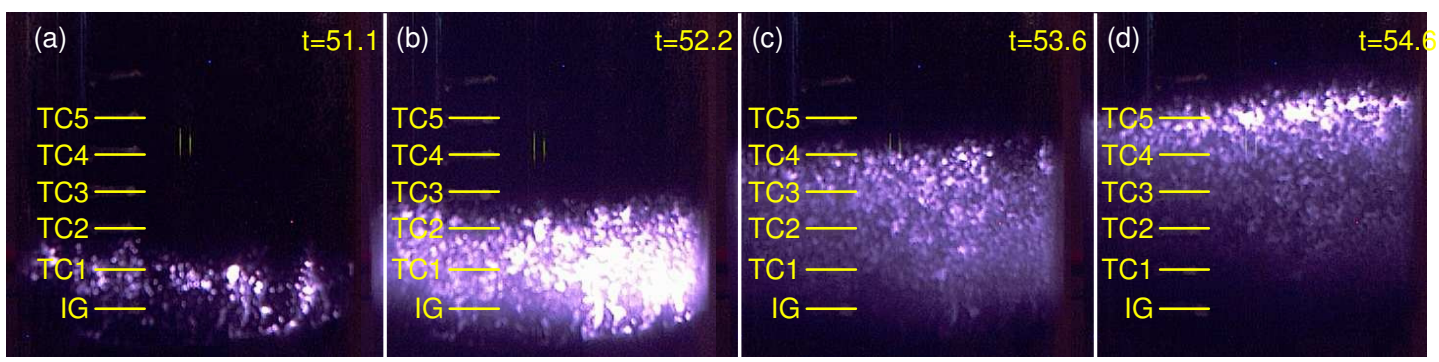

Figure 5. Series images showing the onset and propagation of the visible front for an air flux of $16.2 \mathrm{~cm} / \mathrm{s}$ and a coal tar saturation of $25 \%$. Numbers indicate the position of the thermocouples and the distance in $\mathrm{cm}$ from the igniter (IG). Times are in minutes; note that ignition initiates at $\mathrm{t}=50.0 \mathrm{~min}$.

Figure 6 compares the propagation of the visible front at the edge with the propagation of the temperature peaks at the core for two experiments, with Figure 6a corresponding to the experiment presented in Figures 2a and 5. Figures $6 \mathrm{a}$ and $6 \mathrm{~b}$ reveal that a good correlation exists between the evolutions of the two fronts, with all curves in each graph exhibiting a similar slope (i.e. spread velocity). Velocities obtained from digital images for the $4.75 \mathrm{~cm} / \mathrm{s}$ and $16.2 \mathrm{~cm} / \mathrm{s}$ air flux experiments in Figure 6 are $0.91 \mathrm{~cm} / \mathrm{min}$ and $1.23 \mathrm{~cm} / \mathrm{min}$ respectively. These compare well with the velocities of $0.84 \mathrm{~cm} / \mathrm{min}$ and $1.59 \mathrm{~cm} / \mathrm{min}$, respectively, obtained from the thermocouples. The figure illustrates that for the lower air flux the temperature peak coincides well with the leading edge of the visible front, while for the higher air flux the temperature peak precedes the visible front. Since the visible images privilege the edges of the sample, the differences can be indirectly linked to the strength of the reaction through the curvature of the smouldering front. The visible effect of the curvature is to delay the front observed at the walls with respect to the propagation in the centre. At the lower air flux the front curvature would be lower (i.e., the front is flatter) which is indicative of a stronger reaction. This is consistent with the data presented in $\S 4.1$. 

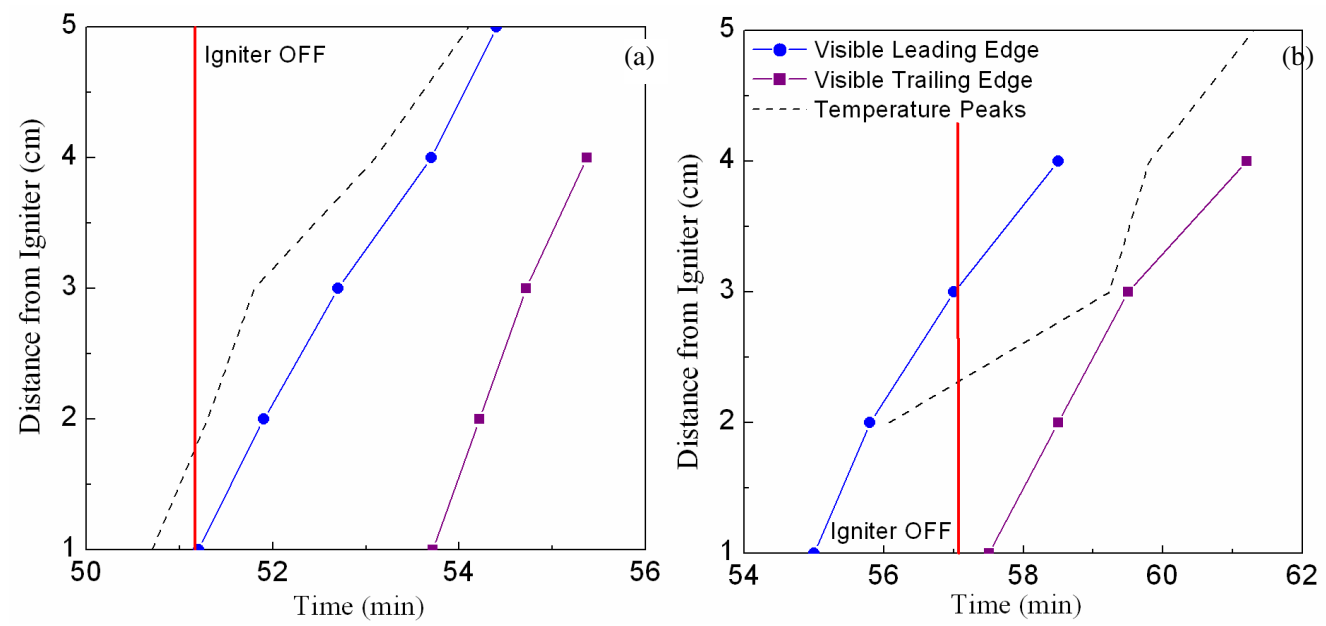

Figure 6. Successive positions of the leading and trailing edges of the front at the apparatus boundary btained from image processing compared with the positions of the temperature peaks along the centre axis for air fluxes of (a) $16.2 \mathrm{~cm} / \mathrm{s}$ and (b) $4.75 \mathrm{~cm} / \mathrm{s}$.

\subsection{Post-treatment Analysis of the Sample}

After each experiment the sand was excavated and the degree of remaining contamination was first visually estimated. As an illustrative example, sand resulting from one of the experiments is showed in Figure 7 compared to clean and contaminated sand. For all the experiments where the reaction was ignited no contamination was detected by visual inspection of sand obtained from the core (i.e., central $80 \mathrm{~mm}$ diameter) of the apparatus (Fig. 7c). A change of the sand colour to red is observed in the treated core. This is attributable to iron oxidation [14] and indicative of exposure to temperatures in excess of $600{ }^{\circ} \mathrm{C}$. Samples taken from the sand adjacent to the beaker walls revealed the presence of some visible residual contamination (Fig. $7 d$ ). This indicates that in the periphery of the sample, heat losses to the external environment caused the quenching of smouldering very close to the wall. Several treated samples were analysed by gravimetric analysis and gas chromatography in order to measure the extent of fuel destruction and removal from the 
Ref: P Pironi, C Switzer, G Rein, JI Gerhard, JL Torero, A Fuentes, Small-Scale Forward Smouldering Experiments for Remediation of Coal Tar in Inert Media, Proceedings of the Combustion Institute 32 (2), pp. 1957-1964, 2009. http://dx.doi.org/10.1016/j.proci.2008.06.184. Free access version at http://www.era.lib.ed.ac.uk/handle/1842/1152

soil. Gravimetric analysis on samples following dichloromethane extraction of all organics revealed average mass removals of $99.95 \%$ for the $80-\mathrm{mm}$ diameter core and $98 \%$ for the periphery. Volatile compounds (e.g., benzene, toluene, ethylbenzene, xylene) were not detected by gas chromatography-mass spectrometry either in the core nor the periphery of the sample.

\section{Conclusions}

A set of small-scale experiments of forward smouldering combustion of liquid coal tar embedded in coarse sand has been conducted for a range of inlet air fluxes and fuel saturations. The progress of the smouldering reaction has been tracked by both thermocouple measurements and visual digital imaging. The combination of these techniques provides valuable insight into the properties of the combustion front. The process has been characterized in terms of average smouldering velocity and peak temperatures as a function of distance from igniter, air flux and initial fuel saturation.
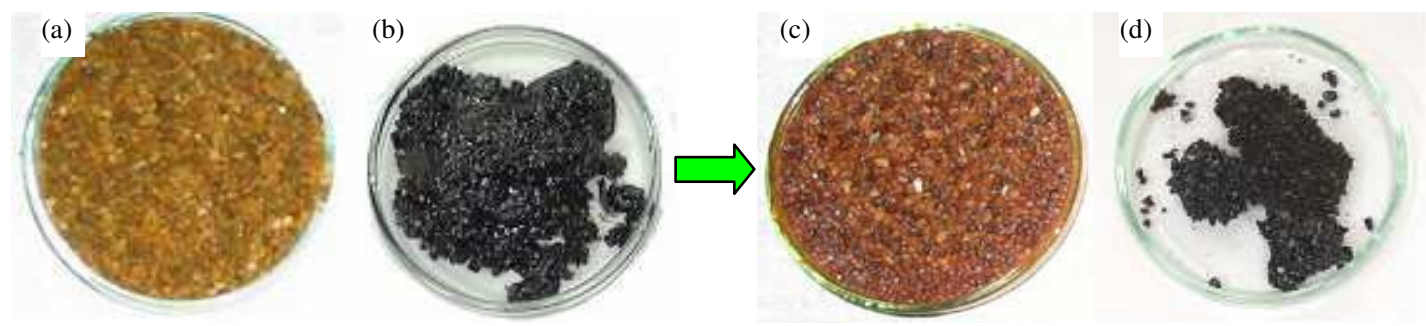

Figure 7. Comparison between samples of sand before and after the treatment: (a) Clean sand, (b) sand mixed with fresh coal tar, (c) treated sand from the core, and (d) treated sand from the periphery of the apparatus.

Results reveal that for all the conditions presented, ignition of the fuel occurred soon after the onset of air injection and self-sustained propagation was established after the igniter was turned off. Peak temperatures were generally highest in the middle of the sample and, decayed towards the top of the sample, but only for the lowest air flux did this appear to 
Ref: P Pironi, C Switzer, G Rein, JI Gerhard, JL Torero, A Fuentes, Small-Scale Forward Smouldering Experiments for Remediation of Coal Tar in Inert Media, Proceedings of the Combustion Institute 32 (2), pp. 1957-1964, 2009. http://dx.doi.org/10.1016/j.proci.2008.06.184. Free access version at http://www.era.lib.ed.ac.uk/handle/1842/1152

result in reaction extinction. The observed temperature decay away from the igniter was attributed to the consequence of igniter-assisted propagation.

Average smoulder velocity shows a nearly linear dependence on the air flux, with a decay of the velocity below the linear trend at low air fluxes. This suggests that, in the range of inlet air fluxes examined, the reaction is oxygen controlled for conditions not approaching extinction. The experiments also show that visual images can be conveniently employed as a detection tool to track the progress of the reaction and that quantitative estimates of the smouldering velocity obtained from images are in good agreement with those produced by thermocouples. Results from tests at varying fuel saturation demonstrate that ignition and self-propagation can be achieved at saturation levels as low as $10 \%$ and show a non-linear dependence of the peak temperature on saturation. Visual inspection and chemical analyses of the sand post-experiments indicate that smouldering combustion significantly the amount of contaminant present in the soil.

These results demonstrate that smouldering combustion is a promising remediation technique for soil contaminated by organic compounds. Prior to implementing this technique in a field trial, further characterization of the reaction dynamics is underway, including the sensitivity to a range of secondary parameters such as soil type and water saturation. Soil type is considered because it is expected that changing grain size and porosity may influence the air distribution in the porous matrix, with possible formation of preferential paths. Water is considered because it represents a significant heat sink, the presence of which is expected to lead to lower reaction temperatures and lower propagation velocities. These and other additional experiments are being conducted at the bench- and field-scales to explore the sensitivity of the remediation process to a suite of in situ and operational parameters.

\section{Acknowledgements}


Ref: P Pironi, C Switzer, G Rein, JI Gerhard, JL Torero, A Fuentes, Small-Scale Forward Smouldering Experiments for Remediation of Coal Tar in Inert Media, Proceedings of the Combustion Institute 32 (2), pp. 1957-1964, 2009. http://dx.doi.org/10.1016/j.proci.2008.06.184. Free access version at http://www.era.lib.ed.ac.uk/handle/1842/1152

This work was supported by Scottish Enterprise and the Engineering and Physical Science Research Council, UK. The authors would like to acknowledge the substantial contribution of Dr. John Jeffrey to the project. The contributions of David Hedges and Wendy Hanson are also acknowledged. A patent application has been filed for this technology.

\section{References}

1. J.F. Pankow and J.A. Cherry, Dense chlorinated solvents and other DNAPLs in ground water, Waterloo Press, Portland, Oregon, 1996.

2. J.W. Mercer, R.M. Cohen, Journal of Contaminant Hydrology 6 (2) (1995) 107-164.

3. J.I. Gerhard, J.L. Torero, C. Switzer, P. Pironi, and G. Rein, In Situ Smouldering Combustion: A Novel Technique for Remediating NAPL Source Zones, Eos Transactions American Geophysical Union 87 (52) (2006), H24A-01 invited talk.

4. D.G. Brown, L. Gupta, T. Kim, H.K. Moo-Young, A.J. Coleman, Chemosphere 65 (2006) 1562-1569

5. J.R. Howell, M.J. Hall, J.L. Ellzey, Prog. Energy Combust. Sci. 22 (1996) 121-145.

6. T.J. Ohlemiller, Progress Energy Combust. Sci. 11 (1985) 277-310.

7. A.G. Merzhanov and B.I. Khaikin, Prog. Energy Combust. Sci. 14 (1998) 1-98.

8. J.L. Torero, A.C. Fernandez-Pello, Combustion and Flame 106 (1-2) (1996) 89-109.

9. A. Bar-Ilan, G. Rein, D.C. Walther, A.C. Fernandez-Pello, J.L. Torero, D.L. Urban, Combustion Science and Technology 176 (12) (2004) 2027-2055.

10. E.A. Salganskii, V.P. Fursov, S.V. Glazov, M.V. Salganskaya, G.B. Manelis, Combustion, Explosion, and Shock Waves 39 (1) (2003) 37-42.

11. J.P. Vantelon, B. Lodeho, S. Pignoux, J.L. Ellzey, J.L. Torero, Proceedings of the Combustion Institute 30 (2005) 2239-2246. 
Ref: P Pironi, C Switzer, G Rein, JI Gerhard, JL Torero, A Fuentes, Small-Scale Forward Smouldering Experiments for Remediation of Coal Tar in Inert Media, Proceedings of the Combustion Institute 32 (2), pp. 1957-1964, 2009. http://dx.doi.org/10.1016/j.proci.2008.06.184. Free access version at http://www.era.lib.ed.ac.uk/handle/1842/1152

12. D.D. Drysdale, Ignition of Liquids (Chapter 18) in: P.J. DiNenno (Ed.), The SPFE Handbook of Fire Protection Engineering (4th ed.), NFPA, Quincy, MA, 2008 (in press).

13. I.Y. Akkutlu, Y.C. Yortsos, Combustion and Flame 134 (2003) 229-247

14. Q.M. Ketterings, J.M. Bigham, Soil Science Society of America Journal 64 (5) (2000) 18261833. 